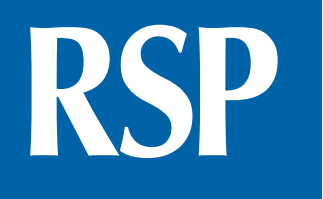

http://www.rsp.fsp.usp.br/

Revista de Saúde Pública

\title{
Report of the procedure of voluntary interruption of pregnancy at a university hospital in Uruguay
}

\author{
Ana Bentancor, Ana Laura Hernández, Yamile Godoy, Juan J Dapueto \\ Departamento de Psicología Médica. Hospital de Clínicas. Facultad de Medicina. Universidad de la República. \\ Montevideo, Uruguay
}

\section{ABSTRACT}

OBJECTIVE: To describe the constitution and operation of a voluntary interruption of pregnancy team of a university hospital, from the outlook of the mental health team.

METHODS: In this case study, the following aspects were analyzed: 1) historical background; 2) implementation of Law 18,897 of October 22, 2012; and 3) functioning of the program at the Hospital de Clínicas of the Facultad de Medicina (Universidad de la República, Uruguay), taking into account three dimensions: structure, process, and results.

RESULTS: Between December 2012 and November 2013, a total of 6,676 voluntary interruptions of pregnancy were reported in Uruguay; out of these, 80 were conducted at the Hospital de Clínicas. The patients' demographic data agreed with those reported at the national level: Of the total patients, $81.0 \%$ were aged over 19 years; $6.2 \%$ decided to continue with the pregnancy; and only $70.0 \%$ attended the subsequent control and received advice on contraception.

CONCLUSIONS: In its implementation year in Uruguay, we can assess the experience as positive from the point of view of women's health. Our experience as a mental health team at the Hospital de Clínicas, inserted into the multidisciplinary voluntary interruption of pregnancy team, is in the process of assessment and reformulation of practices.

Correspondence:

Ana Laura Hernández

Hospital de Clínicas

Av. Italia, 2870 piso 15

11600 Montevideo, Uruguay

E-mail: ahernandez@fmed.edu.uy

Received: 19 Nov 2014

Approved: 16 Aug 2015

How to cite: Bentancor $A$,

Hernández AL, Godoy Y, Dapueto

JJ. Report of the procedure of

voluntary interruption of pregnancy

at a university hospital in Uruguay.

Rev Saude Publica. 2016:50:38.

Copyright: This is an open-access article distributed under the terms of the Creative Commons Attribution License, which permits unrestricted use, distribution, and reproduction in any medium, provided that the original author and source are credited.

DESCRIPTORS: Abortion, Induced, legislation \& jurisprudence. Abortion, Legal. Patient Care Team. Program Evaluation. Health Human Resource Training. Comprehensive Health Care. 


\section{INTRODUCTION}

In ancient societies, abortion did not mean a moral problem. Since the early days of Christianity, the ethical and moral aspects of abortion began to be discussed. In the year of 1869, Pope Pius IX proclaimed the theory of immediate hominization or ensoulment (the moment at which a human being gains a soul) at the moment of conception, an idea that has been maintained by the Catholic Church to the present day ${ }^{6}$. Since the early $20^{\text {th }}$ century, in Uruguay, abortion was criminalized, except in four situations: rape, honor of the woman's husband or father, economic distress, and serious risk to the woman's health.

Being considered a crime, most of the consultations had to do with post-abortion complications, and was followed by a complaint to the health authority. The fear of penalty led to the late appointment and high morbidity and mortality rates ${ }^{1}$.

In 2004, ISCAPCR (Health Initiatives Against Unsafe Abortion) model ${ }^{2}$ was implemented, which proposed two interviews: a pre-abortion, to control pregnancy and inform and prevent the risk of the procedure; and a post-abortion, to rehabilitate the patient holistically and implement measures of contraception. This process culminated with the approval of Law 18,987, which enables the voluntary interruption of pregnancy (VIP) within the first 12 weeks of gestation for the Uruguayan women, minors or adults, and for foreign women residing in the country. The term extends to 14 weeks in case of rape, and throughout the pregnancy, in case of risk to the woman's health or fetal abnormalities incompatible with life outside the womb.

VIP healthcare teams have a gynecologist, a specialist in mental health, and a specialist in the social area. The procedure consists of four stages ${ }^{1}$.

- VIP 1: appointment with physician or midwife, for information and performance of an ultrasound scan and blood group.

- VIP 2: interviews with the multidisciplinary team for information and advice for making a final decision. Five days of reflection must elapse before the VIP 3.

- VIP 3: if the patient confirms her decision, the gynecologist prescribes the medication (mifepristone and misoprostol). The procedure is usually performed on an outpatient basis, but it may be on an inpatient basis. Otherwise, a perinatal record is made. This is the only stage in which the gynecologist can have a conscientious objection.

- VIP 4: appointment with gynecologist for control and diagnosis of possible complications and to provide advice on contraception. If the woman fails to attend her appointment, she is contacted by telephone.

The purpose of this study was to describe the operation of the VIP healthcare team of the University Hospital, from the perspective of mental health professionals. The aim of this communication is to provide local and regional working groups with relevant information about this first stage of work, since Uruguay is the first country in the region to implement a program of sexual and reproductive health of this kind.

\section{METHODS}

In this case study, we conducted the analysis of the structure, process and results of the VIP program of the Hospital de Clínicas of the Facultad de Medicina, Universidad de la República (UdelaR), in Uruguay, after its first year of application ${ }^{3}$.

Patients were assisted in the Gynecological Polyclinic, according to the four stages provided for in the regulation.

In the psychological interview, the aim was to facilitate the decision-making process autonomously, avoiding giving advice and value judgments as well as to determine any support 
resource requirements. A guideline for the performance of the mental health professional (Table 1) was created.

All information was gathered from medical records following the registration form provided by the Ministry of Public Health, which includes an informed consent form. In the interview by the mental health professional, the following issues were taken into account: personal psychiatric history, stressful life events in the past year, social and family support, and the presence of psychosocial problems.

\section{RESULTS}

Between November 2012 and November 2013, 80 patients attended the VIP Polyclinic of the Hospital de Clínicas. Sociodemographic characteristics are listed in Table 2. Average age was 27 years, and most of the women were single. Out of the patients with a psychiatric history $(\mathrm{n}=8,10.0 \%)$, most were associated with depression.

Out of the 80 patients: three (3.8\%) were not pregnant; five (6.3\%) continued with the pregnancy; four (5.0\%) exceeded the 12 weeks of gestation at the time of the first appointment; 11 (13.8\%) were lost in the follow-up; and 57 (71.3\%) attended the VIP 2 appointment.

Gynecologic and obstetric data are listed in Table 2. The most common reason for interruption was unwanted pregnancy, followed by: chronic diseases that can affect the health of the mother and child; stage of life with plans incompatible with motherhood; and family difficulties.

Table 1. Guideline for the performance of the mental health professional of the VIP advice teams.

Specific objective

Joint objectives of the interdisciplinary team

Guideline for the interview

General climate of the interview

Topics to discuss

Interventions

Neutrality and excluded topics
Provide elements that promote decision making ability autonomously, and identify any specific support resource requirements

Detect biopsychosocial risk situations and manage appropriate actions Assess the woman's desire to call the father

Enable possible new appointment before the fifth day, if desired

- Avoid delayed care

- Promote a space with adequate privacy

- Ensure a climate of acceptance

- Ensure confidentiality

- Suggest and give the option of being accompanied by a supportive person during the process

- Always use the term voluntary interruption of pregnancy

- Avoid using terms with moral, religious, or philosophical connotations

- Do not be mobilizer (interview style)

- Avoid confrontations that promote distress

- Talk about the decision-making process

- Assess mental health status

- Assess personal history related to mental health

- Assess the relationship with the father

- Contribute to psychosocial diagnosis

- Articulate in the risk profile and manage actions

- Inform that emotional pain is part of a normal process

- Connect with mental health team, if necessary

- Make a new appointment if the patient wants

- Do not offer advice

- Do not alarm

- Do not impose philosophical or personal convictions

- Refrain from value judgments

- Refrain from preventing or promoting the VIP

- Do not perform a psychotherapeutic interview

VIP: voluntary interruption of pregnancy 
Table 2. Sociodemographic and gyneco-obstetric data. Hospital de Clínicas, Montevideo, Uruguay, 2012-2013.

\begin{tabular}{|c|c|c|}
\hline \multirow[t]{2}{*}{ Age } & $\begin{array}{c}\text { Average: } 27 \text { years old } \\
\text { Minimum } 16 \text { years old } \\
\text { Maximum } 42 \text { years of old } \\
\end{array}$ & SD: 7.3 \\
\hline & $\mathbf{n}$ & $\%$ \\
\hline \multicolumn{3}{|l|}{ Occupation } \\
\hline Housework & 22 & 31.9 \\
\hline Employee & 13 & 18.8 \\
\hline Student & 12 & 17.4 \\
\hline Unemployed person & 8 & 11.6 \\
\hline No data & 14 & 20.3 \\
\hline \multicolumn{3}{|l|}{ Marital status } \\
\hline Married or common-law union & 16 & 23.2 \\
\hline Single & 40 & 58.0 \\
\hline Divorced or separated & 4 & 5.8 \\
\hline No data & 9 & 13.0 \\
\hline \multicolumn{3}{|l|}{ Education level } \\
\hline Primary & 1 & 1.4 \\
\hline Secondary & 7 & 10.1 \\
\hline Tertiary & 4 & 5.8 \\
\hline No data & 57 & 82.6 \\
\hline \multicolumn{3}{|l|}{ Origin } \\
\hline Montevideo & 54 & 78.3 \\
\hline Inland & 6 & 8.7 \\
\hline No data & 9 & 13.0 \\
\hline \multicolumn{3}{|l|}{ Accompanied by } \\
\hline Nobody & 23 & 33.3 \\
\hline Couple & 10 & 14.5 \\
\hline Children & 2 & 2.9 \\
\hline Father or mother & 3 & 4.3 \\
\hline Other & 4 & 5.8 \\
\hline No data & 27 & 39.2 \\
\hline \multicolumn{3}{|l|}{ Psychiatric history } \\
\hline Depression & 6 & 8.7 \\
\hline Addictions & 1 & 1.4 \\
\hline Domestic violence & 3 & 4.4 \\
\hline SA & 2 & 2.9 \\
\hline Others & 1 & 1.4 \\
\hline No history & 5 & 7.3 \\
\hline No data & 51 & 73.9 \\
\hline \multicolumn{3}{|l|}{ Reason for VIP } \\
\hline Unwanted pregnancy & 36 & 52.2 \\
\hline Chronic pathology & 6 & 8.7 \\
\hline Family difficulties & 1 & 1.4 \\
\hline Others & 1 & 1.4 \\
\hline No data & 20 & 36.3 \\
\hline \multicolumn{3}{|l|}{ Date of gestation (week) } \\
\hline$<5$ & 1 & 1.5 \\
\hline 5 & 6 & 8.7 \\
\hline 6 & 9 & 13.0 \\
\hline
\end{tabular}

Continue 
Table 2. Sociodemographic and gyneco-obstetric data. Hospital de Clínicas, Montevideo, Uruguay, 2012-2013. Continuation.

\begin{tabular}{lcc}
\hline 7 & 14 & 20.3 \\
8 & 9 & 13.0 \\
9 & 9 & 13.0 \\
10 & 8 & 11.6 \\
11 & 2 & 2.9 \\
12 & 2 & 2.9 \\
13 & 3 & 4.4 \\
No data & 6 & 8.7 \\
Contraception & & \\
Yes & 24 & 34.8 \\
No & 3 & 4.3 \\
No data & 42 & 60.8 \\
Contraception method & & \\
Condom & 9 & 37.5 \\
OC & 10 & 41.6 \\
IUD & 5 & 20.8 \\
\hline
\end{tabular}

SD: standard deviation; SA: suicide attempts; VIP: voluntary interruption of pregnancy; OC: oral contraceptives; IUD: intrauterine device

Out of the 57 patients who attended the VIP 2 appointment, 50 (87.7\%) completed the VIP 3 appointment and, therefore, received the medication. Out of them, $41(82.0 \%)$ continued the process on an outpatient basis, and $9(18.0 \%)$ were admitted to the hospital. In three cases $(6.0 \%)$ the procedure had to be completed with curettage.

Thirty-seven patients (74.0\%) attended the VIP 4 appointment and $13(26.0 \%)$ were lost in the follow-up. Mortality was zero for the study group.

\section{DISCUSSION}

After a year of the implementation of the VIP law, a total of 6,676 procedures ( $41.0 \%$ in the public subsector and $59.0 \%$ in the private subsector ${ }^{7}$ ) were reported. From the cases, $64.0 \%$ corresponded to the capital Montevideo and $36.0 \%$ to inland. The data gathered are in compliance with those reported at the national level, with: $82.0 \%$ of procedures in women over $20 ; 6.2 \%$ of cases continuing with the pregnancy; and only $70.0 \%$ attending VIP $4^{7}$. We observed that unwanted pregnancies often resulted from failure or lack of contraception. It has been shown in previous studies that $43.0 \%$ of unplanned pregnancies are the result of improper use of contraceptive methods, and that $52.0 \%$ are caused by lack of use ${ }^{7}$.

The constitution of multidisciplinary teams was different in the different institutions involved. In many cases, they did not includ gynecologists, who claimed conscientious objections (up to $30.0 \%$ of them in some departments in the country). As it has happened in other countries, this principle has been difficult to determine, so that it did not incur in non-compliance with the principle of autonomy'.

In the Hospital de Clínicas of UdelaR, a work team with high technical and human quality, seeking a care based on respect, containment, and adequate and necessary information has been consolidated. The integration with the VIP team helped us to better understand women exposed to this problem. Although the psychological interview does not arise from the demand of patients, it is received with willingness and valued as an opportunity. In this sense, we consider important to continue opening lines of work that allow us to explore some aspects related to women's mental health in specific relation to the VIP procedure. Some studies show that women who performed an abortion have similar or lower levels of depression and anxiety 
than women who were denied the abortion by advanced gestational age ${ }^{5,8}$. These results then do not support the idea that abortion is one of the causes of main incidence of mental health problems. It would be very useful, to bring us closer to this perspective regarding population welfare, to be able to implement the most appropriate intervention strategies.

An additional aspect to consider is the emotional impact on teams. The following has been useful in this regard: rotation of tasks; voluntary participation in the VIP team; existence of a space for exchange and supervision; and academic support of the institution.

We have also identified areas to improve program implementation. No additional human resources were made available, so an extra effort by professionals was required. The facility available for care of patients is shared with the gynecologic and obstetric polyclinic, where sometimes interviews are interrupted. As part of this limitation, the registration was affected in the first stages, which explains the lack of data on the analyzed forms. From the point of view of the formation of human resources, we consider the low presence of stages of interinstitutional exchange and discussion as a difficulty.

Our experience as specialists in mental health within an academic and multidisciplinary VIP team, is in process of assessment, reformulation and adaptation of practices.

The work presented here has several limitations. This is a case study, merely descriptive of the characteristics of the patients treated in the mental health facility; in addition, it provides summarized information on the institutional procedure. However, its function is to communicate an innovative experience in our country.

In terms of results, it is preliminary data that require further exploration. We think that it is an innovative experience for a South American country, which can be input for professionals from countries of the region in which the theme begins to be discussed.

\section{REFERENCES}

1. Briozzo L. La despenalización del aborto como estrategia hacia una práctica segura, accesible e infrecuente. Rev Med Urug. 2013;29(2):114-7.

2. Briozzo L, Lavandera A, Gorgoroso M, Pons JE. Iniciativas sanitarias: nueva estrategia en el abordaje del aborto de riesgo. In: Briozzo L, editor. Iniciativas sanitarias contra el aborto provocado en situaciones de riesgo. Montevideo: Arena, 2007.

3. Donabedian A. Evaluating the quality of medical care. Milbank Q. 2005;83(4):691-729.

4. Fiala C, Arthur J. "Dishonorable disobedience": why refusal to treat in reproductive healthcare is not conscientious objection. Woman - Psychosom Gynecol Obstet. 2014;1:12-23. DOI:10.1016/j.woman.2014.03.001

5. Foster DG, Steinberg J, Roberts SC, Neuhaus J, Biggs MA. A comparison of depression and anxiety symptom trajectories between women who had and abortion and women denied one. Psychol Med. 2015;45(10):2073-82. DOI:10.1017/S0033291714003213

6. Garrido Calderón J. El aborto en la historia. Rev Med Dom. 1995;17(1):30-3.

7. Ministerio de Salud Pública. República Oriental del Uruguay. Balance implementación de la Ley 18.987 -Interrupción Voluntaria del Embarazo. Decreto 375/012. Reglamentación de la ley de IVE. Diciembre 2012 - Mayo 2013. [citado 2016 abr]. Disponible en: http://www. medicosdelmundo.org.uy/IMG/pdf/conferencia_prensa_ive_julio_2013.pdf

8. Steinberg JR, Rubin LR. Psychological aspects of contraception, unintended pregnancy, and abortion. Policy Insights Behav Brain Sci. 2014;1(1):239-47.

Authors' Contribution: Development and planning of the article: AB, ALH. Data analysis and interpretation: AB, ALH, YG, JJD. Writing of the document, critical review and final approval of the document: AB, ALH, YG, JJD.

Conflict of Interests: The authors declare no conflict of interest. 